\title{
Author/Subject Indexes Vol. 13, No.3-4, 1995
}

Ballermann, B·J· 125 Bucala,R. 160 Burkart, J.M. 180 England, B.K. 147 Golper,T.A. 111 Kelley,V.R. 199 Mclntire, L.V. 112 Ott,M.J. 125 Patrick, C.W., Jr. 112

Paul,L.C. 206 Pereira, B.J.G. 135 Piraino,B. 171 Price, S.R. 147 Sanders, P.W. 219 Strom, T.B. 199 Vlassara,H. 160 Ward,R,A. 153

Acidosis 147

Advanced glycosylation endpro-

ducts 160 Allograft 199 Antigen presentation 199 L-Arginine 219 Biocompatibility 135

Branched-chain $\alpha$-ketoacid dehy-

drogenase 147

amino acids 147 Chronic rejection 206

renal failure 147 Clearance 153

Continuous ambulatory peritonitis 171

Cyclic strain 112 Cyclosporine 219 Cytokines 135 Diabetes 160 mellitus 219

Dialysis 135 - access 125 Dialyzer reuse 153 Differentiation 125 Dyslipidemia 160 Endothelin 112 Endothelium 112 Gene expression 112 Glomerulosclerosis 219 Glucocorticoids 147 Growth factors 206 Hemodialysis 153 Hypertension 219 Immune reactions 206 Interleukins 135 Kidney 199 LDL 160

Middle molecules 160 Monocytes 135 Nitric oxide 219

Nutrition 180

Peritoneal dialysis 171,180

-, future trends 180 Proteasome 147 Protein degradation 147 Rejection 199 Remnant kidney 219 Renal failure 219

hemodynamics 206 Shear stress 112, 125 Signal transduction 112 Staphylococcus 171 T cells 199 Tolerance 199 Transplantation 199,206 Ubiquitin 147 Uremia 160 Vascular grafts 125 Water purification 153 